\title{
GERAÇÕES CONTEMPORÂNEAS, CIBERCULTURA \& AS PERSPECTIVAS E DESAFIOS NA FORMAÇÃO DO PROFESSOR DE HISTÓRIA.
}

\author{
Patrícia Marcondes de Barros \\ (Doutora em História - UNESP)
}

\section{RESUMO}

O presente artigo, interface do trabalho realizado em estágio pós-doutoral, tem como objetivo geral analisar quais são as perspectivas e os desafios educacionais na formação dos professores de História, frente a um mundo complexo relacionado às tecnologias de informação e comunicação que expressam através das gerações contemporâneas, uma nova subjetividade relacionada à pós-modernidade. Delimitaremos nossa discussão acerca do "novo formato de aluno" frente aquilo que Pierre Levy conceitua como cibercultura e a necessidade do professor de se empoderar das novas tecnologias, entendendo-as como balizadoras dos novos paradigmas que se impõe no campo educacional. Afora à sociedade utilitária que se indaga do "para quê serve a História?", do presenteísmo das novas gerações e da precarização da Educação no contexto brasileiro atual, a formação de professores de história se constitui por si mesma, em um grande desafio, originado ainda na graduação nos cursos de licenciatura e depois, profissionalmente, através de formação continuada.

Palavras-Chave: Gerações Contemporâneas, Cibercultura, Formação Docente.

\section{INTRODUÇÃO}

Neste artigo analisaremos quais são os desafios na formação dos professores de História frente às novas gerações moduladas pelas mudanças paradigmáticas que alteraram o modo de pensar, produzir, consumir (CASTELLS, 1999) e consequentemente, de 'ensinar e aprender', relacionadas à pós-modernidade, o que leva a necessidade contínua de revisão e construção constante de saberes, no cotidiano pessoal e profissional.

Atualmente, observamos no ambiente escolar o encontro geracional dos chamados "baby-boomers" e da geração " $\mathrm{X}$ " (geralmente personificadas na figura dos pais e professores) com as advindas do mundo tecnológico; jovens e crianças denominados: "Y", "Z" e "alpha", que tem gerado um sentimento de 'estranhamento" pelas diferentes expectativas e perspectivas que possuem em relação à educação, apresentadas tanto em suas formas (metodologias, meios e linguagens) quanto em conteúdos (novos discursos que abarquem a complexidade e singularidade dos "nativos digitais"). A inabilidade do professor em relação a um novo formato de aluno acarreta em dificuldades relacionais que reverberam no processo de ensino e aprendizagem, levando à indisciplina, violência, evasão escolar, entre outros problemas enfrentados cotidianamente no Brasil (BARROS, 2015).

Afora as dificuldades relacionais, o professor de História (assim como o de outras áreas) vivencia em seu cotidiano, as dicotomias entre a docência e a pesquisa, as novas teorias e metodologias com a racionalidade instrumental dos objetivos e metas 


\section{SEMINÁRIO DE PESQUISA EM CIÊNCIAS HUMANAS - SEPECH \\ Humanidades, Estado e desafios didático-científicos \\ Londrina, 27 a 29 de julho de 2016}

das empresas voltadas à Educação (instituições privadas de Ensino); e no âmbito público, a precarização do ensino brasileiro (BARROS, 2015). Torna-se uma exigência para o docente neste contexto, aprender constantemente "o novo", criando articulações com as realidades e diversidades existentes no âmbito educacional e outras áreas do conhecimento; utilizar novas estratégias de motivação, se empoderando das novas tecnologias para interagir com um aluno que, independente da classe social, nasceu sob a égide da tecnologia.

Anterior ao imperativo que comumente se coloca ao professor face à contemporaneidade, de se apropriar de forma instrumental das novas tecnologias (tratando-as como um 'entendimento neutro', sem ideologia), faz-se necessário analisar as mudanças paradigmáticas trazidas por este aparato 'pós-moderno' e seus impactos na cultura escolar.

A partir do entendimento das perspectivas e expectativas das novas gerações, denominadas também de "nativos digitais", comumente imersos na cibercultura, analisaremos de forma geral, quais são os desafios postos à formação docente pela cultura contemporânea, com suas rupturas de paradigmas científicos, tecnológicos e éticos, seu poder de distribuição dos bens socioculturais e de criação de sistemas de interpretação do mundo.

Num primeiro momento, apresentaremos quem são os "novos alunos" chamados de cibernativos, categorizados sociologicamente como geração: "Y", "Z" e "alpha"; e posteriormente, analisaremos a formação de professores de História neste devir. Este se depara com uma sociedade brasileira cada vez mais retrógrada, onde pautas conservadoras avançam e expressam discursos lineares e homogêneos, amparados pelas instituições políticas. Antagonicamente ao subdesenvolvimento brasileiro, vivemos em um mundo globalizado e "conectado" através da rede, marcado pela diversidade e complexidade.

\section{AS NOVAS GERAÇÕES CIBERNATIVAS: OS MEIOS COMO EXTENSÕES DO INDIVÍDUO CONTEMPORÂNEO}

Como afirma o teórico Marshall McLuhan: "os meios são a extensão do homem", ou seja, as novas ferramentas tecnológicas são sinalizadoras de novas maneiras de saber ser, sentir e pensar que emergiram em fins do século XX, na década de 80, com a denominação "sociedade da informação" ou "pós-industrial" e que trouxeram avanços significativos, assim como, dilemas para a vida individual e coletiva (CASTELLS, 2000).

No âmbito educacional, tais avanços e mudanças são facilmente perceptíveis e vão desde as novas tecnologias aplicadas à educação, ao comportamento diferenciado e complexo da criança e do jovem atual.

Green e Bigum (APUD FÁVERO SOBRINHO, 2002) têm se destacado por estabelecer a diferença histórica entre o aluno de "ontem" com o "de hoje". Afirmam que os alunos que estão em nossas escolas são radicalmente diferentes dos alunos de épocas anteriores por apresentarem uma "historicidade pós-moderna", constituída por um conjunto de práticas culturais responsáveis pela produção de sujeitos particulares, específicos, com identidades e subjetividades singulares. 


\section{SEMINÁRIO DE PESQUISA EM CIÊNCIAS HUMANAS - SEPECH \\ Humanidades, Estado e desafios didático-científicos \\ Londrina, 27 a 29 de julho de 2016}

O "novo aluno" constrói de forma diversa suas narrativas no mundo contemporâneo abrangendo diversas linguagens, desde as poéticas e as imagéticas até as meramente tecnológicas (FÁ VERO SOBRINHO, 2002). Segundo Neto (2010, p.12), crianças e jovens sob a égide de uma realidade tecnológica e virtual avançada com: celulares, telecomputadores, Ipods, videogames, vídeo e televisores com alta definição em 3D, games jogados em redes sociais, entre outros, construíram sua subjetividade dentro de uma lógica diferenciada de seus pais e professores. A categorização das gerações para análise não significa apenas em classificar genericamente pela faixa etária (pois existem outros conceitos explicativos), contudo, nos conduzirá no concernente a compreensão das tendências relacionadas às novas subjetividades.

A instabilidade e a transitoriedade difundidas de forma característica entre os cibernativos estão intrinsecamente relacionadas às condições pós-modernas que produzem uma esfera "líquida", com pouca segurança psicológica, econômica e intelectual. $\mathrm{O}$ mundo moderno inaugurado no século XIX, das previsibilidades, deu lugar a um planeta no qual o tempo e o espaço são condensados pela virtualidade, onde crianças e jovens, sem pertencerem a algum lugar concreto, vão vivendo progressivamente espaços culturais e sociais mutáveis, marcados por uma pluralidade de linguagens e culturas (GIROUX,1996).

Esses indivíduos "pós-modernos" formam o que se denominou como Geração "Y", "Z" e "Alpha", oriundos desse ambiente de liquidez de significados e de grande desenvolvimento tecnológico.

A chamada geração "Y", digital ou "Millenniums" são representadas pelas crianças que nasceram na década de 80 até meados de 1992. Foram profundamente marcadas pela Revolução Tecnológica, pela globalização e a necessidade de assumir a sustentabilidade como bandeira de preservação do planeta. Nascidas em um tempo no qual o consumo se expandiu e foi facilitado pela tecnologia, são geralmente preocupados com o sucesso profissional, sem a perspectiva ideal de outrora, em se estabilizar no mesmo emprego ou empresa. A busca profissional será por parte dessa geração, pelos melhores salários, o que implica na possibilidade de consumir o que o mundo tem a oferecer (NETO, 2010, p.13) e por condições de trabalho flexibilizadas à vida pessoal e social (tão importantes quanto a profissional). $\mathrm{Na}$ aprendizagem são mais afeitos às imagens do que aos textos. Isto significa que os professores, emigrantes digitais, se esforçam para ensinar (e compreender) os alunos que utilizam linguagens completamente novas e uma comunicação com ênfase no digital (FAVA, 2012).

A Geração "Z", chamada também de "geração silenciosa", é composta por indivíduos que nasceram a partir de 1993, predominantemente no mundo virtual (NETO, 2010, p.14). A denominação " $Z$ ” vem do verbo 'zapear', quando o indivíduo costumeiramente muda de um canal para outro na televisão. Segundo Neto (2010,p.14) tal geração se caracteriza por crianças e jovens que vão da internet para o telefone, do telefone para o vídeo e retornam novamente à internet. Assim como se utilizam dos meios tecnológicos, também 'trocam' de uma visão de mundo para outra, instantaneamente, tal como o funcionamento dos computadores e a navegação no

\footnotetext{
${ }^{1}$ A esfera líquida a que me refiro se relaciona com as ideias de Zigmunt Bauman quanto a pósmodernidade. Bauman define modernidade líquida como um momento em que a sociabilidade humana experimenta uma transformação que pode ser sintetizada na dissolução dos discursos e práticas lineares, do sentido da história e das instituições que outrora regiam a vida social e a conduta dos indivíduos.
} 


\section{SEMINÁRIO DE PESQUISA EM CIÊNCIAS HUMANAS - SEPECH \\ Humanidades, Estado e desafios didático-científicos \\ Londrina, 27 a 29 de julho de 2016}

espaço virtual com os hiperlinks. ${ }^{2}$ Sua comunicação se dá em rede, é contínua, realizando multitarefas, todas com ênfase no tempo 'presente', na perspectiva de resultados rápidos e aplicabilidade dos conteúdos escolares na vida profissional (NETO, 2010, p.14).

Já as crianças do século XXI, denominadas de "Alpha", desde tenra idade tem a capacidade de criar e compartilhar conteúdos no ciberespaço com autonomia, pois dominam a cultura digital e utilizam suas ferramentas para produzir conteúdos (CAMBOIM; BARROS, 2010). Alguns autores postulam sobre a eminência do "fim da infância" (POSTMAN, 1999) ou que a mesma é inexistente atualmente, posto que uma construção do adulto. Contudo, existe no universo infantil, uma resistência e apropriação que na miríade de possibilidades da cultura digital, permite a criança construir, reelaborar e interagir à cultura postulada pelos adultos. A infância se transforma ao sabor da velocidade digital, mudando sua feição, não por características biológicas, mas culturais (ALCANTARA;CAMPOS, 2006).

Segundo Tânia Casad (APUD LOIOLA, 2010), crianças e jovens contemporâneos possuem tecnologia wireless, ou seja, são aptos à capacidade da convergência de mídias, à cultura não apenas interativa, mas participativa.

Sobre a cultura de convergência das mídias na esfera educacional, Fava explica:

(...)não deve ser compreendida apenas como um processo tecnológico dentro ou fora da sala de aula. Mais do que isso, a convergência representa uma transformação cultural, uma vez que os estudantes são incentivados a procurar e colocar novas informações nos mais diversos sistemas e fazer conexões em meio a conteúdos de informações dispersos, criando assim, a cultura participativa e não mais apenas a cultura interativa(FAVA, 2012, p. 08).

Dentro dessa perspectiva de cultura de convergência, presume-se que novas e antigas metodologias de ensino e aprendizagem irão interagir de forma cada vez mais complexa, ressignificando o papel do professor e das instituições escolares.

\section{A FORMAÇÃO DO PROFESSOR DE HISTÓRIA NO CONTEXTO DOS CIBERNATIVOS}

Dentro do cenário atual, percebe-se que as práticas docentes estão defasadas, não se enquadrando as novas formas e linguagens a que os alunos estão imersos na contemporaneidade. Existe uma inabilidade premente em se lidar com as novas gerações, devido a idealizações que muitas vezes perpassa a própria subjetividade e experiência do professor, além de uma formação docente dicotômica. A formação para

\footnotetext{
${ }^{2}$ Hiperlinks consistem em links que vão de uma página da Web ou arquivo para outro(a). Quando um visitante do site clica no hiperlink, o destino é aberto, executado ou mostrado em um navegador da Web, dependendo do tipo de destino. Com frequência, o destino é outra página da Web, mas pode também ser uma figura, um arquivo multimídia, um documento do Microsoft Office, um endereço de email ou um programa. Por exemplo, um hiperlink para uma página exibe essa página no navegador da Web e um hiperlink para um arquivo MID abre o arquivo em um mídia player. (fonte: Frontpage - Ajuda)
} 


\section{SEMINÁRIO DE PESQUISA EM CIÊNCIAS HUMANAS - SEPECH \\ Humanidades, Estado e desafios didático-científicos \\ Londrina, 27 a 29 de julho de 2016}

o professor de História é iniciada na universidade no modelo $3 \mathrm{X} 1^{3}$, que separa a teoria da prática profissional, o que na referida área se reduz praticamente a docência ${ }^{4}$. Existem outras dicotomias e paradoxos, como ensinar História dentro de uma realidade política que não permite a pluralidade de pensamentos ideológicos devido aos segmentos políticos reacionários que hoje dominam a sociedade brasileira (a exemplo da promulgação do projeto "Escola Livre", chamada também de "Lei da Mordaça",), perpassando pela própria "inutilidade" atribuída a disciplina por uma visão utilitária advinda da sociedade tecnocrática capitalista. Contudo, junto ao subdesenvolvimento brasileiro caminha o "novo", afinal, a perspectiva da cultura digital presume diversificação e complexidade cultural, estas advindas do ciberespaço, 'lugar' desterritorializado que rompe com a linearidade dos discursos (e da pretensa lógica calcada ainda no século XIX, com o Positivismo), a concepção de tempo/espaço, tendo como proposta a horizontalidade das relações humanas.

As transformações culturais propiciadas pela cibercultura se dão então não apenas pelos aparatos tecnológicos, mas principalmente pelos tipos de signos que circulam nesses novos meios engendrando mensagens e processos de comunicação (SANTAELLA, 2003, p.24). Com o advento da cultura digital e sua universalização, as interações sociais e a produção de conhecimento são amplamente transformadas através da virtualidade. Em relação a este conceito, Lèvy (1999) a distingue como o "real desterritorializado", visto que se apresenta de forma não linear/contínua, sem as coordenadas de tempo e espaço. Portanto, cabe ressaltar que, segundo o autor, o virtual não se opõe ao real, nem ao material, ao contrário, o exponencia dentro do espaço físico do computador. O mote de suas obras vincula-se as proposições acerca da nova relação que o indivíduo estabelece com o saber através do ciberespaço, que acaba por amplificar, exteriorizar e modificar funções cognitivas humanas como o raciocínio, a memória e a imaginação levando, segundo alguns visionários, a mutação da espécie.

(...)A cibercultura, tanto quanto quaisquer outros tipos de cultura, são criaturas humanas. Não há uma separação entre uma forma de cultura e o ser humano. Nós somos essas culturas. Elas moldam nossa sensibilidade e nossa mente, muito especialmente as tecnologias digitais, computacionais, que são tecnologias da inteligência, conforme foi muito bem desenvolvido por Lévy e De Kerckhove. Por

\footnotetext{
${ }^{3} \mathrm{O}$ modelo " $3+1$ " é assim chamado porque se referia a três anos de estudos teóricos na área disciplinar, acrescidos de um ano de formação pedagógica, ao final dos quais o estudante estaria pronto para enfrentar a sala de aula (CERRI, 2013, p.170)

${ }^{4} \mathrm{O}$ campo da pesquisa na área das Ciências Humanas é também uma possibilidade para quem ingressa no curso de História. Contudo, sabemos que existe uma grande demanda de pesquisadores sem condições de exercerem sua ocupação (sem bolsas que incentivem e propiciem a dedicação à pesquisa), ou seja, para permanecerem na profissão na qual se formaram, necessariamente serão professores de História. Nesse sentido, acredito que a graduação, da forma como se constitui nos planos curriculares atualmente, não consiga nem formar um "bom professor de história" e tampouco, um pesquisador.

${ }^{5} \mathrm{O}$ deputado Ronaldo Medeiros (PMDB), presidente interino da Mesa Diretora da Assembleia Legislativa de Alagoas (ALE-AL), promulgou a lei $n^{\circ} 7.800$, conhecida como Escola Livre, que defende "neutralidade" política, ideológica e religiosa do professor em sala de aula. Para garantir a efetividade da lei, o projeto prevê punições previstas no Código de Ética e no regimento único dos servidores, que estipula até demissão.
} 


\section{SEMINÁRIO DE PESQUISA EM CIÊNCIAS HUMANAS - SEPECH \\ Humanidades, Estado e desafios didático-científicos \\ Londrina, 27 a 29 de julho de 2016}

isso mesmo, são tecnologias autoevolutivas, pois as máquinas estão

ficando cada vez mais inteligentes (SANTAELLA, 2003, p.30).

Segundo Santaella (2003, p.27-28), a cibercultura molda uma nova sensibilidade através da cultura do acesso, que corrobora e convergem todas as formas de comunicação e de cultura em um caldeamento denso e híbrido que vai desde a comunicação oral e escrita à cultura de massas e das mídias, responsável pelo nível de exacerbação da produção e circulação da informação na contemporaneidade.

O ofício do professor de História neste devir deve se abrir a miríades de possibilidades trazidas por essa convergência midiática, com a eclosão de "novos meios e mensagens" que reverberam linguagens diferenciadas em sua forma e conteúdo.

Frente às complexas realidades presentes no ambiente escolar o professor deve colocar um fim em suas certezas absolutas. Afirma Perrenoud (APUD SANTOS, 2009, p.7169): "o educador deve fazer o luto das certezas didáticas, pois o terreno das práticas educativas é bem mais incerto do que fazia supor o cristalino positivismo das suas análises". Assim sendo, faz parte do processo histórico em que vivemos estar disponível a aceitar as incertezas e se lançar a novas experiências, construindo novos paradigmas, reaproximando a prática da teoria em relação às demandas contemporâneas e também específicas, regionais, locais, culturais do ambiente escolar.

Para Santos (2009), o papel do professor no contexto de incertezas não é propriamente o de promover e desenvolver uma ação com sentido moral, mas sim, de levar a cabo uma ação com significado social, político e reflexivo.

Ao professor de História (que leciona tanto presencialmente quanto em EAD) faz-se necessário ter em sua formação docente, conhecimento das transformações oriundas da cibercultura que desvelam as experenciações humanas contemporâneas. Segundo Silva (2010), a formação dos professores para docência presencial ou online necessita apreender essencialmente as quatro exigências da cibercultura: entender a transição da mídia clássica para a online, se apropriar das diversas linguagens que comportam o hipertexto, conceber a interatividade no processo de construção do conhecimento (horizontalizando as relações entre professor/aluno), potencializar a comunicação e a aprendizagem utilizando de forma apropriada interfaces da internet.

Segundo Silva (2010), não existe uma situação material e formativa adequada de docência e aprendizagem de História numa perspectiva cibercultural. No ensino presencial em escolas públicas brasileiras, a exemplo, muitas vezes depara-se com o livro didático como a única "tecnologia" disponível a que o professor faz uso.

A formação docente se constitui neste contexto e por si mesma um grande desafio, pois se por um lado, vivenciamos um mundo de grandes possibilidades advindas da cibercultura, por outro, enfrentamos a precariedade estrutural ocasionada por questões políticas/sociais que expressam o subdesenvolvimento no campo educacional.

\section{CONSIDERAÇÕES FINAIS}

Este artigo teve como objetivo discutir de forma geral, a questão da formação do professor de História frente a um novo formato de aluno, imerso na cibercultura, que assinala perspectivas e expectativas diferenciadas em relação à Educação. Faz-se 


\section{SEMINÁRIO DE PESQUISA EM CIÊNCIAS HUMANAS - SEPECH \\ Humanidades, Estado e desafios didático-científicos \\ Londrina, 27 a 29 de julho de 2016}

necessário à formação docente compreender essa nova subjetividade para ações educativas que contemplem a nova realidade escolar.

Souza (2003) faz as seguintes afirmações sobre a profissão de professor:

É importante entender, o que já é consenso, que o magistério e a profissão de professor caracterizam-se como uma profissão com níveis de complexidade, exigindo revisão e construção constante de saberes, centrando seu saber ser e fazer numa prática reflexiva e investigativa do trabalho educativo e escolar, no cotidiano pessoal e profissional. Desta forma, compreendo que o desenvolvimento profissional entrecruza-se com a dimensão pessoal e político-social do professor, enquanto profissional numa realidade contextualizada (SOUZA, 2003, p.441).

Neste sentido, os níveis de complexidade da profissão docente acompanham dimensões que vão além de novas aprendizagens e metodologias atualizadas. A complexidade incide na condição existencial do docente que congrega vários sentidos e saberes os quais convergem para aspectos objetivos e subjetivos de sua identidade (SOUZA, 2003). Assim sendo, a formação docente presume mudanças individuais e coletivas, o que implica em um descondicionamento daquilo que se entendia como educação, professor, instituições escolares, passando pela concepção de História e de se ensinar tal disciplina.

\section{REFERÊNCIAS}

ALCÂNTARA, A.C.; ROMERO, M. A infância entre o desaparecimento e a reinvenção. In: SAMPAIO, Inês Sílvia Vitorino; CAVALCANTE, Andréa Pinheiro Paiva e ALCÂNTARA, Alessandra Carlos (org). Mídia de chocolate: estudos sobre a relação infância, adolescência e comunicação. Rio de Janeiro: E-papers, p.139-150, 2006.

BARROS, P.M.D. Os conflitos geracionais e os desafios na formação docente na contemporaneidade. Revista Internacional de Diversidad e Identidad em La Educación. Vol. 03, no.1, Madrid, 2016.

CAMBOIM, A.F.L; BARROS,A.C.P. RELACIONAMENTO MERCADOLÓGICO COM OS CIBERNATIVOS NA INTERNET. In Anais do XII Congresso de Ciências da Comunicação na região Nordeste. São Paulo: INTERCOM, 2010, v.1.

CASTELLS, M. Sociedade em rede. Paz e Terra, São Paulo, 2000.

CERRI, L.F. A formação dos professores de História no Brasil: antecedentes e panorama atual. História, histórias. Brasília, vol. 1, no.02, 2013.

FAVA, R. Educação 3.0: como ensinar estudantes com culturas tão diferentes. 2 ed. Cuiabá: Carlini e Caniato Editorial, 2012. 


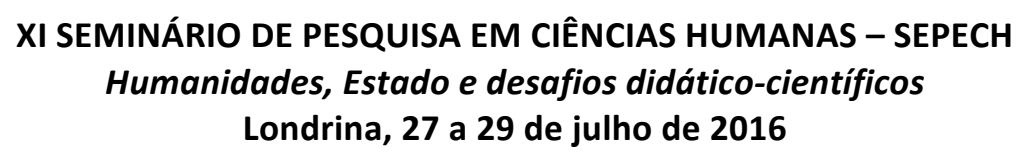

FÁVERO SOBRINHO, A. O ALUNO NÃO É MAIS AQUELE! E AGORA, PROFESSOR? A TRANSFIGURAÇÃO HISTÓRICA DOS SUJEITOS DA EDUCAÇÃO. Anais do I Seminário Nacional: Currículo em movimento Perspectivas Atuais. Belo Horizonte, novembro de 2010.

GATTI, B. A. Pesquisa, Educação e Pós-Modernidade: Confrontos e Dilemas. Cadernos de Pesquisa, v. 35, n. 126, set./dez. 2005. http://www.scielo.br/pdf/cp/v35n126/a04n126.pdf

GIROUX, H. Jovens, diferença e educação pós-moderna. In: Castells M, Flecha R, Freire P, Giroux H, Macedo M, Willis P. Novas perspectivas críticas em educação. Porto Alegre (RS): Artes Médicas; 1996. p.63-85.

LEVY, Pierre. O que é o virtual. São Paulo: Ed. 34, 1996.

. Cibercultura. São Paulo: Ed. 34, 1999.

NETO, E.S; FRANCO, E.S. OS PROFESSORES E OS DESAFIOS PEDAGÓGICOS DIANTE DAS NOVAS GERAÇÕES: CONSIDERAÇÕES SOBRE O PRESENTE E O FUTURO. Revista de Educação do COGEIME - Ano 19 - n.36 - janeiro/junho 2010 .

POSTMAN, N. O desaparecimento da infância. Trad. Suzana Menescal de A. Carvalho, José Laurenido de Melo. Rio de Janeiro: Graphia, 1999.

SANTAELLA, L. Culturas e artes do pós-humano: da cultura das mídias à cibercultura. São Paulo: Paulos, 2003.

SANTOS, A. R. J. FORMAÇÃO DO PROFESSOR NA CONTEMPORANEIDADE: REPENSANDO CONCEITOS E POSSIBILIDADES. IX Congresso Nacional de Educação - EDUCERE. III Encontro Sul Brasileiro de psicopedagogia. 26 a 29 de outubro - PUC-PR, 2009.

SILVA, M. Educar na cibercultura: desafios à formação de professores para a docência em cursos on line. Revista digital de tecnologias cognitivas. PUC -São Paulo, no. 3 (janeiro-junho), 2010. 